\title{
Tensionamentos maternos na contemporaneidade: articulações com o cenário brasileiro
}

Maternal Tensionings in Contemporaneity: Articulations with the Brazilian Scenario

Tensions maternelles à la contemporanéité : articulations avec le scénario brésilien

\section{Ana Luiza de Figueiredo Souza}

\section{OpenEdition}

\section{Journals}

Edição electrónica

URL: http://journals.openedition.org/rccs/10972

DOI: $10.4000 /$ rccs. 10972

ISSN: 2182-7435

\section{Editora}

Centro de Estudos Sociais da Universidade de Coimbra

Edição impressa

Data de publição: 1 dezembro 2020

Paginação: 47-68

ISSN: 0254-1106

\section{Refêrencia eletrónica}

Ana Luiza de Figueiredo Souza, «Tensionamentos maternos na contemporaneidade: articulações com o cenário brasileiro », Revista Crítica de Ciências Sociais [Online], 123 | 2020, posto online no dia 15 dezembro 2020, consultado o 17 dezembro 2020. URL : http://journals.openedition.org/rccs/10972 ; DOI : https://doi.org/10.4000/rccs. 10972 


\section{ANA LUIZA DE FIGUEIREDO SOUZA}

\section{Tensionamentos maternos na contemporaneidade: articulações com o cenário brasileiro*}

Do Norte ao Sul global, cresce o debate sobre a maternidade. Neste contexto, o Brasil desponta enquanto profícuo campo investigativo. Como país que tanto preserva ideologias conservadoras quanto absorve novas manifestações tecnológicas e culturais, apresenta fenômenos particulares que estabelecem diálogo com práticas estrangeiras. Este trabalho explora as conjunturas socioculturais em torno da proliferação de discussões sobre a maternidade, objetivando encontrar semelhanças e divergências entre as dinâmicas brasileiras e as dos demais países. Para isso, o artigo contextualiza movimentos históricos que conduziram até à atual situação das mulheres e da maternidade no Ocidente capitalista; perscruta as tensões na convivência entre práticas contemporâneas e historicamente construídas; e debate até que ponto se dão os processos de continuidade ou ruptura entre elas.

Palavras-chave: Brasil; condição feminina; feminismo; identidade feminina; maternidade; saúde da mulher.

\section{Introdução}

Há alguns anos, especialmente nos países ocidentais capitalistas, discussões sobre a maternidade com abordagem personalista ganharam maior abrangência em palestras, ${ }^{1}$ eventos, ${ }^{2}$ livros ${ }^{3}$ e programas televisivos. ${ }^{4}$ Este movimento

\footnotetext{
* Este artigo baseia-se, em parte, na dissertação de mestrado da autora (Souza, 2019), vencedora do Prêmio Compós de Teses e Dissertações Eduardo Peñuela e finalista no Prêmio UFF de Excelência - Colégio de Humanidades.

${ }^{1}$ Entre elas, as palestras do TEDx Talks "Maternidade real", da youtuber brasileira Helen Ramos; "My Choice to Live Child-Free" ("Minha escolha de viver sem filhos"), da ensaísta e advogada estadunidense Christen Reighter; e "The Lost Tribe of Childless Women" ("A tribo perdida das mulheres sem filhos"), da psicanalista inglesa Jody Day.

${ }^{2}$ Como o Seminário Internacional de Mães, no Brasil, e as conferências da MIRCI - The Motherhood Initiative for Research and Community Involvement, organização que promove o debate dos estudos maternos formada por pesquisadoras de diferentes países.

${ }^{3}$ Conforme se vê em BookAuthority (s.d.), "100 Best Motherhood Books of All Time". Consultado a 20.07.2019, em https://bit.ly/2XWxK8f.

${ }^{4}$ Por exemplo, o programa "Quando Tudo Começa", no canal Discovery Home \& Health, e a série "Turma do Peito", da Netflix.
} 
tem crescido no Brasil, sobretudo nas mídias sociais. ${ }^{5}$ Por meio de narrativas pessoais, diferentes mulheres ${ }^{6}$ se apropriam dessas plataformas para debaterem a maternidade a partir de suas vivências maternas: conjunto de valores e ideologias relacionados à maternidade que cada mulher - via convívio familiar, instituições de ensino, cotidiano social, produções midiáticas - adquire ao longo da vida. Tal conjunto ajuda a estabelecer o lugar que elas reservam à maternidade dentro de seu planejamento pessoal e a forma como a enxergam em termos coletivos (Souza, 2019). A prática de tratar questões coletivas através de experiências particulares alinha-se ao que van Zoonen (2012) identifica como novo modo de consumir e produzir discursos voltados à defesa de pautas, fomentando uma relação mais autocentrada com a política e a esfera pública.

Por ser um país que tanto preserva costumes e ideologias conservadoras quanto absorve novas manifestações tecnológicas e culturais, o Brasil configura um profícuo campo investigativo, apresentando fenômenos particulares que estabelecem diálogo com práticas estrangeiras. Diante das consideráveis modificações de paradigmas em torno da maternidade ocorridas em anos recentes e de sua reduzida discussão acadêmica, apresentar as dinâmicas brasileiras a ela relacionadas pode trazer elucidações sobre processos semelhantes em demais países.

Assim, este artigo dedica-se a explorar as conjunturas socioculturais em torno da proliferação de discussões sobre a maternidade, tendo o Brasil, especialmente no âmbito das mídias sociais, como foco. ${ }^{7}$ Objetiva-se encontrar paralelos e divergências entre movimentações brasileiras e estrangeiras.

$\mathrm{Na}$ primeira parte do artigo, contextualizam-se movimentos históricos que conduziram à atual situação das mulheres e da maternidade no Ocidente capitalista. A segunda seção explora as tensões na convivência entre práticas contemporâneas e historicamente construídas, abordando as ambiguidades da cultura do consumo e seu impacto tanto em modelos maternos e de maternagem ${ }^{8}$ (o trabalho de criar e educar aqueles/as tidos como filhos/as),

\footnotetext{
${ }_{5}^{5}$ Plataformas digitais que permitem modos comunicativos bi e multidirecionais entre os usuários, bem como a visibilidade de conteúdos por eles criados (Lemos, 2002).

${ }^{6}$ Sobretudo aquelas com acesso regular à Internet.

${ }^{7}$ Detalhes sobre conteúdos relacionados à maternidade nas mídias sociais brasileiras disponíveis nos Anais do XVI Seminário de Alunos de Pós-graduação em Comunicação - PÓSCOM 2019, em http://bit.ly/2YVTWhB. Consultado a 03.07.2020.

${ }^{8}$ Aqui cabe apontar que a maternagem pode ser entendida enquanto a prática cotidiana e a própria performance da maternidade, isto é, a rotina de atividades e comportamentos que classificam uma mulher como mãe de seus/suas filhos/as. Todavia, a maternagem, por si só, não é suficiente para que alguém seja considerada mãe. Babás, avós, professoras, tias e madrinhas comumente desempenham tarefas relacionadas à maternagem das pessoas (em geral crianças, mas pode-se incluir adolescentes, jovens adultos/as ou adultos/as com necessidades especiais) sob seus cuidados. Isso não significa necessariamente que as enxerguem enquanto filhos/as, nem que estes/as as vejam como suas mães.
} 
quanto nas construções identitárias e subjetivas das mulheres. $\mathrm{O}$ terceiro tópico debate até que ponto se dão os processos de continuidade ou ruptura com preceitos maternos e sociais historicamente construídos. Por fim, o trabalho apresenta os apontamentos finais sobre as discussões nele engendradas.

\section{Progressões históricas e dinâmicas contemporâneas}

No início da década de 1960, o ativismo feminista dos Estados Unidos da América (EUA) e da América Latina passou a discutir a influência que estruturas sociais de ordem patriarcal tinham sobre a vida cotidiana, familiar e íntima das mulheres. Tal movimento, somado à entrada massiva de mulheres nas universidades e no mercado de trabalho, desencadeou protestos e uma presença mais incisiva das mulheres nos espaços de poder. Até aos anos 1950, as feministas brasileiras evitavam ao máximo espelhar a aparência e os comportamentos masculinos para pontuarem suas diferenças e, a partir delas, fazerem demandas. Já nos anos 1960, para serem levadas a sério em ambientes ainda dominados por homens, buscavam, assim como outras feministas ocidentais, se afastar tanto da imagem conservadora e santificada da mãe quanto de representações que pudessem prejudicar o reconhecimento de seu desempenho na esfera pública (Rago, 2004). Encaravam a maternidade e os atributos a ela ligados como marcas da dominação contra a qual lutavam - o que se alinhava a correntes feministas francesas que a reconheciam enquanto um defeito natural (bandicap), que confinaria as mulheres em uma bioclasse.

Logo, a recusa da maternidade seria o primeiro caminho para subverter a dominação masculina e possibilitar que as mulheres buscassem uma identidade mais ampla, mais completa e, também, pudessem reconhecer todas as suas outras potencialidades. (Scavone, 2001: 139)

O número crescente de pesquisadoras nos centros de produção acadêmica ao longo das décadas de 1970 e 1980 tornou necessário reformular ou mesmo descartar conceitos misóginos, masculinizados, incapazes de acolher manifestações que se distanciassem da concepção do sujeito histórico universal como masculino, branco, heterossexual, de países considerados desenvolvidos (Rago, 1998). Assim, as teorias feministas surgem para ampliar o escopo das experiências históricas dignas de serem narradas, ressignificando-as. Se nos anos 1960 o corpo foi negado ou negligenciado e a postura das feministas se assemelhava a de oradoras avessas à maternidade e à imagem tradicional da mãe, a partir dos anos 1980 percebe-se a busca 
de novos lugares para o feminino (Rago, 2004). É nessa década inclusive que a questão da saúde das mulheres entra na agenda feminista brasileira.

Incomodadas e insatisfeitas com o fato de o corpo da mulher e sua saúde serem traduzidos e orientados pelos médicos - ginecologistas e obstetras -, bem como com a perspectiva fragmentada de sua corporalidade por eles propalada, as feministas passam a reivindicar um tratamento específico e integral à saúde feminina. Nesse sentido, em busca de um outro olhar, menos patológico, menos reprodutor e menos intervencionista, a saúde torna-se um dos pontos de grande ataque e remodelação feminista. (Carneiro, 2011: 2)

Enquanto movimento e teoria, o feminismo nacional tentava ampliar a questão da maternidade, tornando-a mais amparada e reconhecida. Tal postura permite traçar um paralelo com a corrente do feminismo diferencialista, mais forte na Itália e na Espanha. Nela, a maternidade é assumida como parte da história e identidade femininas, sendo considerada um poder insubstituível que só as mulheres possuem (Scavone, 2001). Por meio de seus corpos, o feminismo passa a construir novas formas de feminilidade, novas concepções sobre beleza, sedução, saúde e sexualidade. Rago (2004) indica a possibilidade de uma reinvenção subjetiva das feministas, na qual se põe em prática a constituição estilizada da própria subjetividade, desenvolvida em um momento em que a liberdade, nos seus mais variados sentidos, é experimentada de forma mais intensa.

A identidade pós-moderna passa a ser um empreendimento reflexivamente organizado, e em certa medida maleável, de modo a que o projeto reflexivo do eu permita mudanças conforme se alteram os interesses individuais. Isso em muito se liga à possibilidade de as pessoas planejarem seus projetos de vida no período moderno com objetivos que não eram, ao contrário do que ocorria nas sociedades tradicionais, predeterminados por instâncias sociais, ${ }^{9}$ e sim por motivações próprias. $\mathrm{Na}$ contemporaneidade, esse quadro se acentua sob a forte influência do mercado capitalista. Não há escolha senão escolher (Giddens, 1991): a cultura do consumo apresenta uma série de ofertas e, para a integrarem, as pessoas devem eleger quais delas consumir. Só existem discussões sobre desejar ou não ser mãe ou sobre que tipo de maternidade se pretende exercer em um contexto em que podemos arquitetar, ao menos até certo ponto, nossos projetos de vida. A partir do momento em que se pode escolher com mais abrangência, ainda que desigualdades sociais e históricas interfiram no poder de escolha de

\footnotetext{
${ }_{9}$ Embora estas ainda influenciem muitas das escolhas empreendidas.
} 
cada pessoa, coexistem posicionamentos diversos, que elaboram projetos de vida em disputa.

Diante da possibilidade de, enquanto sujeitos femininos, vivenciarem experiências até então restritas e, como pós-modernas, planejarem seus projetos e estilos de vida, as mães contemporâneas passam a compor a imagem da mulher independente, pois, além de emancipada e muitas vezes chefe de família, quer ter prazer sexual, sentir-se atraente e dedicar tempo para cuidar de si mesma (Rago, 2004). Isto se relaciona com a moral da boa forma enunciada por Sibilia (2010), na qual se exige, sobretudo da mulher, uma performance estética ligada ao que se entende como corpo saudável e ativo, que ganha importância na vivência materna. Não basta estar feliz com os/as filhos/as, é preciso perceber-se charmosa, disposta, o que tanto pode permitir novas experimentações corpóreas quanto gerar desconforto diante da imagem no espelho que não reflete os ideais esperados de cuidado e beleza.

Donath (2017) aponta a transformação nos parâmetros do que se entende por "boa mãe". Se, no passado, refletia a imagem da Virgem enquanto persona assexuada, pura e sacralizada, a partir da década de 1980 o modelo mitológico intensificou a representação das mães - especialmente de classe média, brancas e jovens - como seres sexuais e objetos eróticos.

Essas novas representações da figura materna não significam que a sociedade encare seu corpo como algo totalmente atraente, mas sim que elas se tornam cada vez mais desejáveis como objetos de fantasias sexuais, ao mesmo tempo que fomentam outras fantasias míticas de que as mães "têm tudo". Hoje é quase uma certeza que uma mulher não deveria 'apenas' ser mãe. Se você quiser ser reconhecida, também precisa ter uma profissão, participar ativamente na pré-escola e na escola durante o pouco tempo livre de que dispõe e ser, apesar de toda a exaustão, sexy, é claro. (ibidem: 54-55)

Espera-se que o corpo das mães atenda aos mesmos padrões heteronormativos que o mito da beleza e da sexualidade impõe às mulheres em geral. O corpo materno não está livre da busca pelo aprimoramento estético, da conservação de traços joviais nem da obrigação de exibir uma disponibilidade sexual muito mais ligada às expectativas de terceiros do que aos seus próprios desejos.

Outro aspecto se destaca na citação acima de Donath: o nível de exigência para com as mães é muito maior do que em épocas anteriores. Para dar conta das cobranças (inclusive autoinfligidas), precisam otimizar o tempo em uma maternagem e rotina baseadas na ideia de alta performance. A influência mercadológica que resulta na necessidade de pensar projetos 
de vida também repercute na maternidade. Crianças e mães representam uma importante parcela do mercado capitalista, gerando o consumo de produtos e serviços cada vez mais variados e lucrativos. Há interesse comercial na maternidade, sobretudo em modelos maternos e de maternagem que demandem grande investimento financeiro da parte das mães - em si mesmas e nos/nas filhos/as. Somam-se a isso mães-empreendedoras cujos negócios, muitas vezes, se dirigem ao universo materno.

Os anos 1990 marcam a maior preocupação dos movimentos feministas em tratar das especificidades nas demandas de cada mulher, de acordo com recortes étnicos, afetivos, econômicos e socioculturais. No Brasil, estudos analisam as condições de vida das mulheres negras, indígenas, campesinas e imigrantes, levando à criação de programas voltados à prevenção e tratamento do câncer de colo de útero e/ou de mama, amamentação, atenção ao parto e contenção da mortalidade materna pelo Ministério da Saúde (Carneiro, 2011). De forma mais ampla, trata-se do debate sobre a construção do que se entende por identidade feminina, em uma tentativa de ampliar os preceitos hegemônicos que a sustentavam até então. Em 1992, essa vontade política e acadêmica de uma revisão do feminismo enquanto movimento e teoria é denominada terceira onda feminista - ou pós-feminismo, como preferem algumas autoras - que se define enquanto "a existência, hoje, de uma multiplicidade de feminismos, ou de um feminismo plural, que reconhece o fator da diferença como uma recusa da hegemonia de um tipo de feminismo sobre outro" (Macedo e Amaral, 2005: 154). Nesse contexto, o conceito de gênero também é repensado, inaugurando a teoria queer.

Uma de suas principais representantes, Butler (1990), utiliza o termo performatividade - adaptado da linguística e da filosofia - para se referir às práticas regulatórias e de repetição que impõem uniformidade no comportamento estabelecido pela cultura como coerente no que diz respeito a sexo e gênero. Segundo a filósofa, o gênero não é algo que somos, mas algo que fazemos, usando para isso nosso próprio corpo, através de atitudes que remetem ao que se pretende representar. Repetir uma série de atos que foram, ao longo de séculos, estabelecidos cultural e socialmente como femininos é validar-se enquanto sujeito pertencente a este gênero. Performatizar o amor materno, a devoção aos/às filhos/as e o cuidado com a família seria, então, uma forma de construir-se e ser reconhecido como sujeito feminino. Nesse sentido, a recusa da maternidade exporia as mulheres a uma temida pena social, sendo a aceitação de tornarem-se mães mais uma instituição social compulsória do que uma escolha, já que se pretende naturalizar e universalizar tal instituição como própria do gênero feminino. 


\section{Práticas antigas, novas problemáticas}

O termo empregado por Butler (1990) - instituição social compulsória se aproxima da expressão comumente usada em problematizações maternas que, no Brasil, tem destaque nas mídias sociais: maternidade compulsória (Souza, 2019). Consiste em estruturas, desde práticas de socialização até leis, que impelem as mulheres a se tornarem mães. Movimentos e teorias feministas contemporâneos compreendem que não é o fator biológico da capacidade de gestação que determina o lugar social das mulheres, mas as relações de dominação que atribuem à maternidade um significado social (Scavone, 2001). Na esfera dos debates maternos, a maternidade compulsória tende a ser encarada enquanto prática pela qual a conduta feminina é regulada, o que se aproxima da concepção de que

A maternidade não é um projeto privado. É sempre, infinita e exaustivamente, pública. Todos os dias, as mulheres ouvem que possuem essas habilidades instintivamente, por natureza, mas ao mesmo tempo estão submetidas aos ditames sociais sobre como deveriam conduzir a relação com seus filhos de forma a serem consideradas "boas mulheres" e "boas mães", pessoas e seres morais. (Donath, 2017: 53, itálico no original)

Apesar de novas facetas da maternidade terem sido mais abordadas nos últimos anos, a cultura midiática ocidental ainda revela uma supervalorização do papel de mãe, em que discursos que associam a maternidade à dedicação e à plenitude são priorizados em detrimento de discussões mais profundas sobre a maternagem. É o que Douglas e Michaels (2004) chamam de New Momism, que, embora aparente celebrar a maternidade, dissemina padrões de perfeição materna que configuram uma visão intensamente romantizada e exigente da maternagem, em que o pleno sucesso das mães é inatingível. Leal (2015) aponta como importantes revistas brasileiras promovem o modelo identitário da "mulher poderosa" como a síntese do papel feminino contemporâneo. A "mulher bem-sucedida" é aquela que conquistou êxito nos âmbitos do trabalho, casamento, maternidade, beleza e sociabilidade. Os discursos midiáticos, então, engendram subjetividades conformadas tanto aos ideais historicamente construídos de feminilidade (incluindo-se os de zelo e afeição maternos) quanto às demandas produtivistas do capitalismo neoliberal.

Manter as mães informadas por meio de conteúdos produzidos por especialistas também é trivial nas mídias brasileiras (Tomaz, 2016), mesmo que, muitas vezes, as experiências das mães sejam enfatizadas. O tom aparentemente mais inclusivo, que respeita as vivências particulares 
da leitora, espectadora ou ouvinte, pode ser um modo de lidar com narrativas paralelas às do circuito mainstream, produzidas principalmente nas mídias sociais. $\mathrm{O}$ arranjo entre mães, mídias e especialistas se modifica pelas possibilidades de interferência proporcionadas por sistemas de interação online.

Contudo, algumas representações históricas permanecem. Ao analisar anúncios brasileiros e canadenses veiculados entre 2006 e 2013, Mendonça (2014) percebe que a publicidade da mídia impressa reproduz e reforça a maternidade conforme os valores das culturas patriarcal e de consumo. Grávidas são representadas como figuras passivas, assexuadas e inexperientes na maternagem. Mães são puras, meigas e totalmente dedicadas aos/às filhos/as, em oposição ao que suas entrevistadas (todas mães) relataram para a pesquisa. Mesmo ao se esforçarem para conciliar diferentes tarefas e papéis, sentiam que os ideais de perfeição materna afetavam sua autoestima, aumentando a sensação de culpa.

$\mathrm{Na}$ contemporaneidade, o estímulo configura o mecanismo do funcionamento social (Sibilia, 2010), gerando vontades que não estão isentas da influência de construções sociais. Entre elas, a de ser uma mãe presente, que dá conta de diversas atividades ao longo do dia. O que as mães atuais chamam de culpa pode ser lido como a frustração com a própria "ineficiência", suas falhas e inaptidões. Hoje, o estímulo é o mecanismo que incita as mulheres na vida cotidiana, produzindo desejos. Para ter/criar os/as filhos/as, a mãe sacrifica outro desejo, que ambiciona menos. Porém, um dos paradoxos maternos é que a faceta da obrigação - relacionada ao controle - ainda tem forte papel, inclusive dentro desses desejos.

A maternidade é normativa no que se refere à dimensão da norma social. Há determinados comportamentos que as mães precisam ter, alguns estabelecidos por lei; caso contrário, arriscam a se tornarem alvo de exclusões, condenação pública ou perda da guarda dos/das filhos/as. O desejo de virar mãe atrela-se a uma série de obrigações que a mulher não queria necessariamente assumir ao engravidar/adotar. A normatividade materna (Souza, 2019) também se estende à maneira como não mães se referem à maternidade e com ela se relacionam. Determinadas atitudes configuram desvios ao que se espera de sua conduta em relação ao universo materno/feminino, sendo objeto de silenciamento, repreensão, asco. Percebe-se que várias reações (censura, raiva, repúdio) a práticas opostas à normatividade materna se repetem entre mães e não mães. O que muda é como se manifestam de acordo com a condição que a mulher avaliada ocupa. A repulsa atribuída a uma mãe impaciente para lidar com os/as filhos/as é diferente da que se aplica a uma não mãe sem paciência para lidar com os/as filhos/as alheios/as, e assim por diante. 
Em uma cultura que tanto valoriza o cuidado estético - que faz algumas mulheres não desejarem a gravidez/amamentação devido a seus impactos físicos -, muitas mães exigem amamentar os/as filhos/as, chegando a militar a favor da prática. ${ }^{10}$ Contudo, também relatam desconfortos e insatisfações corporais causados por ela. Tem-se assim mais um paradoxo materno: apesar de influenciadas por práticas culturais de valorização das experiências prazerosas (Souza, 2016) e pela moral da boa forma, as obrigações maternas são maiores do que lamentos e hedonismos. Precisam amamentar, pelo bem do bebê, mesmo que isso resulte em feridas, estrias e demais marcas que os parâmetros estéticos e as próprias mães tomam como indesejáveis. Tratam-se de ambiguidades da cultura do consumo, que oferece estímulos abundantes e contraditórios. O contemporâneo é marcado pela tensão entre imposições culturais (ou mesmo governamentais) e desejos particulares; entre a construção do projeto de vida e a tentativa de atender os anseios da sociedade.

Interessantemente, a dor continua legitimando a maternidade: quanto mais dor possui, mais autêntica e significativa se torna. O que as discussões nas mídias sociais do Ocidente chamam de maternidade real é a valorização dos aspectos complicados, estressantes e dolorosos envolvidos na maternagem. ${ }^{11}$ Ao mesmo tempo, existem movimentos de mulheres que querem uma maternidade mais leve, em oposição tanto à ênfase aos sofrimentos maternais quanto ao número exacerbado de exigências às mães. ${ }^{12}$ Os modelos maternos e de maternagem hegemônicos ainda carregam a influência de concepções historicamente construídas (como a mãe ser a principal responsável pelo bem-estar dos/das filhos/as), somadas a exigências de otimização que respondem a novas cobranças e definições femininas advindas, em boa parte, do mercado capitalista. A maternidade se torna mais exigente quando se associa à ideia de sujeito autônomo, ilusão em muito produzida pelo neoliberalismo, que busca suprimir o fato de que qualquer pessoa, direta ou indiretamente, depende das ações de outras.

Diferentes mulheres vão vivenciar e perceber a maternidade de modos distintos. Embora haja especificidades, existem aspectos relacionados à maternidade comuns às mulheres em geral, especialmente no Sul global: os modelos hegemônicos maternos e de maternagem, fundamentados na cultura da maternidade patriarcal, servem de parâmetro para a construção

\footnotetext{
${ }^{10}$ Conforme visto em Santos, Cila (2017), "Das tetas subversivas", blogue Militância Materna, 31 de julho. Consultado a 22.07.2019, em https://bit.ly/2JV91HO.

${ }^{11}$ Como se vê em https://bit.ly/2Y946Im e https://bit.ly/32ECM8h. Consultados a 22.07.2019.

12 Cf. os Anais do XVI Seminário de Alunos de Pós-graduação em Comunicação - PÓSCOM 2019, em http://bit.ly/2YVTWhB. Consultado a 03.07.2020.
} 
da identidade feminina, bem como das expectativas sociais que a circundam; espera-se que mulheres sejam "maternais", isto é, altruístas, ternas, zelosas e que lidem bem com crianças; por serem mães potenciais, enfrentam maior dificuldade para se posicionarem no mercado de trabalho, pois se presume que se afastarão do serviço durante a licença-maternidade e/ou colocarão o/a filho/a acima de seus compromissos profissionais; ter filhos/as ainda é considerado um fator - às vezes o mais importante - para definir a utilidade social e o nível de satisfação pessoal de uma mulher; desde cedo, mulheres são socializadas para se verem enquanto mães na vida adulta; a vinculação entre maternidade e ambiente doméstico, reforçada pela socialização que a coloca como um destino muito provável, mantém as mulheres enquanto principais responsáveis pelas tarefas da casa e a manutenção de sua rotina, como parte do (treinamento para o) exercício da função de mãe.

Caso as vivências maternas fossem tão particularizadas, as centenas de milhares de publicações, vídeos e relatos pessoais acerca do que significa na vida das mulheres não reverberariam em uma parcela tão grande do público feminino. Mães e não mães são excluídas do imaginário social em um mesmo aspecto: enquanto seres complexos que não se restringem à maternidade.

\section{Entre rupturas e continuidades}

A cultura patriarcal sustenta pressupostos ideológicos que, ao definirem o significado da maternidade e da maternagem, as tornam opressivas para as mulheres. Entre eles, segundo O'Reilly (2013), estariam as ideias de que a maternidade é fundamental à identidade feminina; uma tarefa centrada na figura da mãe e restrita à esfera reprodutiva doméstica; natural às mulheres, que saberiam maternar espontaneamente; idealizada por modelos maternais inatingíveis que reforçam as expectativas das mães sobre si mesmas e as da sociedade sobre as mães.

Este último pressuposto se relaciona ao que Badinter (2011) entende como retomada contemporânea de preceitos naturalistas, entre os quais o da vocação materna e o do vínculo instintivo. Todavia, é necessário contestar a ideia de retomada defendida pela autora. Do Brasil Colônia até a Europa dos anos 1940, a culpa das mães e das mulheres sem filhos/as era vinculada à religião e ao dever moral. Apesar de esses aspectos ainda serem relevantes em muitas narrativas pessoais brasileiras sobre a maternidade, prevalecem os sentimentos de insuficiência e de frustração, que em muito se relacionam à lógica do estímulo e do desejo. A culpa é inclusive percebida como equivocada por muitas mães nas mídias sociais, algo que precisam superar (Souza, 2018).

No geral, as mudanças em relação à forma como a maternidade é encarada são mais fortes do que as continuidades com os modelos maternos 
hegemônicos historicamente construídos. Contudo, reconfiguram-se alguns antigos valores atribuídos à maternidade: a demanda das próprias mulheres para parir com dor, em busca de um parto "natural"; a exigência de uma maternagem dedicada; o pesar que tantas sentem por valorizarem a aparência após a gravidez; a forte responsabilização das atitudes das mães. Seria mais adequado considerar que existem novos arranjos e interesses que, na visão de Badinter (2011), dialogam com práticas históricas.

A autora elenca alguns fatores que explicariam a popularização de discursos maternos mais conservadores. $\mathrm{O}$ primeiro remete às sucessivas crises econômicas desde os anos 1980, que resultaram no sacrifício da posição feminina no mercado de trabalho. Por ganharem menos, várias mulheres se recolheram ao ambiente doméstico enquanto os maridos assumiam as contas. Nesse cenário, a Europa e os EUA viram surgir uma geração mais conformista do que a anterior, cuja aspiração se voltava para a maternidade e a vida familiar. Na América Latina, tal modificação não foi tão drástica, já que a maternidade nunca deixou de ser considerada um dos pilares da vida feminina, tendo sido incluída enquanto pauta nas demandas feministas contemporâneas com relativa facilidade (Rago, 2004; Scavone, 2004; Meruane, 2018).

Como segundo fator, há a proliferação do que Badinter (2011) chama de discurso ecopolítico, que censura as indústrias químicas e prega um estilo de vida mais harmônico com o planeta para compensar os longos períodos de exploração e contaminação. Tal iniciativa originou fenômenos como: a diminuição do uso de pílulas anticoncepcionais; a adoção de fraldas de pano, absorventes biodegradáveis, cosméticos não testados em animais, papinhas orgânicas, entre outros produtos femininos/infantis menos "invasivos" e/ou prejudiciais ao meio ambiente (pode-se pensar na popularização do coletor menstrual); e campanhas avessas à mamadeira em prol da amamentação orgânica, defendida como saudável, ecológica e afetiva.

Meruane (2018) compreende tais empreendimentos como parte de um discurso pretensamente avançado, amparado na retórica da ecologia e da vida natural, mas que indica o retorno de um modelo materno e de maternagem conservador, que pretende, sobretudo na América Latina, devolver as mulheres ao confinamento doméstico por meio da reivindicação de práticas como a prolongação do período de lactância, a convivência intensiva com os/as filhos/as e a ampliação da liberdade infantil em detrimento da dos/das adultos/as.

Mais uma vez, cabe questionar se ocorre de fato um retorno, visto que as práticas e formas persistem, mas seus sentidos mudaram. As mulheres 
que escolhem o modelo de maternidade que desejam seguir - mesmo os mais restritivos - encarnam melhor a moral contemporânea de arquitetar projetos de vida. Porém, em uma América Latina (sobretudo no Brasil) que se volta cada vez mais para agendas políticas e discursos reacionários, é importante ressalvar que as construções sociais impactam tanto quais escolhas se apresentam como elegíveis quanto quais se decide empreender.

Os aspectos destacados por Meruane integram o terceiro fator que Badinter elenca para a repaginação contemporânea de preceitos naturalistas: a posição que a criança adquiriu nas últimas décadas no núcleo familiar, tornando-se o centro da maioria dos esforços realizados pela família. É preciso compreender a psique da criança, visitar seu universo lúdico, guiá-la rumo a descobertas e desafios. Revistas, sites e consultórios elegem a mãe como a principal responsável pelo desenvolvimento (psíquico, físico, sociocultural) dos/das filhos/as, assim como a maior culpada por suas desavenças. Por mais que estejam em curso reivindicações para que os pais ${ }^{13}$ e demais agentes (familiares, escolas, governos) participem de maneira mais proativa na criação dos/das filhos/as, as mães permanecem as maiores encarregadas pela rotina deles/as, além dos cuidados com a casa e com a carreira. É o que Meruane (2018: 16) denomina "reciclagem atual da mãe-empregada", e que também pode ser lida como maternagem de alta performance.

O último fator se relaciona à representação apaziguada da maternidade feita pela mídia e por mulheres que, enquanto profissionais, mães ou amigas, recomendam uma maternagem intensa, "de livre demanda", condenando aquelas que não podem ou não querem seguir tais princípios. Apesar do crescimento de um discurso semelhante ao naturalista, o sofrimento é muitas vezes suprimido nas experiências maternais no que se relaciona aos/às filhos/as. Acrescentam-se cobranças e sacrifícios às mães para poupá-los/las de possíveis transtornos. Por um lado, essa prática opera na lógica

\footnotetext{
${ }_{13}$ Em 2016 e 2019, o Instituto Promundo publicou a primeira e a segunda edições do relatório Situação da paternidade no Brasil, com o objetivo de embasar profissionais interessados/as em desenvolver políticas públicas de valorização do cuidado paterno. Saúde, diversidade, afeto, mercado de trabalho, prevenção da violência, equidade entre gêneros, incidência política e primeira infância são algumas das esferas que os documentos associam à paternidade, atentando para o fato de que, inicialmente, o debate público brasileiro centrava-se na ausência dos pais e/ou de seu zelo na vida dos/das filhos/as. Os relatórios respondem a questionamentos recentes acerca do papel masculino tanto na criação daqueles e daquelas que se tomam por filhos/as (ou demais pessoas sob seus cuidados) quanto na manutenção ou ruptura de estruturas que, muitas vezes, tornam a maternidade opressiva para as mulheres. Todavia, cabe destacar que os homens (pais ou não pais) e a paternidade ainda são pouco acionados em discussões sobre as dificuldades enfrentadas por mães e não mães (Souza, 2019), indicando que muitas mulheres que delas participam não os veem como direta ou parcialmente responsáveis por alguns aspectos de suas vivências maternas.
} 
contemporânea da alta performance e da estimulação intensificada. Uma experiência materna mais completa incluiria maior quantidade de desafios a serem superados, que validariam tal vivência como legítima, ativa e interessante. Por outro, relaciona-se tanto à valorização da criança quanto ao discurso ecopolítico que prega uma reaproximação com métodos menos intervencionistas, que remetam aos "comandos da natureza".

O excesso passou a integrar as experiências de gravidez e puerpério no Brasil (Dramali, 2018). Em uma vertente, tem-se exacerbado intervencionismo científico, como análises sobre as predisposições genéticas do bebê, agendamento do parto com meses de antecedência, preferência por procedimentos cirúrgicos e uso de suplementos alimentares/acessórios específicos ao longo da gestação. Na outra vertente, encontra-se o parto sem remédios, sem aparelhos, sem a figura do/da médico/a, etapa final de uma gravidez encarada como mais orgânica, seguida por um puerpério que busca conforto em outros métodos para além dos comprimidos. Em ambos os posicionamentos, fica clara a valorização do poder de decisão das mães. Mediado ou "natural", é preciso que o modelo seja uma escolha consciente. Tal princípio se reflete no discurso dos movimentos feministas brasileiros sobre o parto: critica-se mais a imposição de uma determinada prática contra a vontade da mãe, e não necessariamente a prática em si. Há maior demanda para decidir como gerenciar o próprio corpo e o que se faz com ele.

A esfera corporal ganha relevância na maternidade, embora haja muita desinformação sobre os aspectos que a constituem e, entre as camadas populares, conforme aponta Scavone (2004), mais limitações em relação à conduta médica. Não é raro profissionais e programas de saúde agirem de forma impositiva quanto às populações com menor poder aquisitivo ou socialmente marginalizadas. Mulheres do campo e da floresta, indígenas e periféricas (especialmente as mulheres negras), por exemplo, costumam ser alvo de comportamentos impositivos por parte dos/das médicos/as e enfermeiros/as, com reduzidos meios de exigir ou encontrar condutas alternativas. Tais imposições se dão tanto em relação à maternidade quanto à não maternidade, abarcando políticas de controle populacional, acesso a tratamentos para fertilidade e/ou métodos cirúrgicos para não gerar filhos/as, entre outros procedimentos.

Donath (2017: 61) explica que a maternidade é socialmente construída de forma a elencar comportamentos e sentimentos associados às imagens da "boa mãe" e da "mãe ruim". Enquanto a primeira se dedica aos/às filhos/as com zelo, sustenta-os/as, expressa amor, preocupação e altruísmo, a mãe ruim tem dificuldade para lidar com suas obrigações (afetivas ou financeiras), sente raiva e frustração. Quando as atitudes ou sentimentos de 
uma mulher se aproximam da imagem da mãe ruim (mesmo que não tenha filhos/as), ela tende a ser encarada como problemática, incapaz de estar à altura de seu "verdadeiro destino". Todavia, a antropóloga identifica um amplo espectro de atitudes emocionais que oscilam entre "uma tendência para a maternidade" e "uma tendência para a não maternidade", que pode ser expresso por uma mesma mulher, seja mãe ou não (Donath, 2017: 21). Complexifica-se assim a oposição binária "mãe" e "não mãe", que muitas vezes fomenta a rivalidade entre mulheres.

Para Meruane (2018: 21), o ataque às que escolhem não ter filhos/as é a reação de muitas mães diante da "aprazível ou exultante certeza das mulheres-sem-filhos", que revela o "enorme esforço de racionalização" que essas mães tiveram que empreender para conduzir a maternidade. Podemos pensar que as mulheres sem filhos/as também se engajam em práticas e discursos que buscam valorizar o fato de não serem mães, tendo como possível efeito colateral a depreciação da imagem materna.

Somado às abdicações e obstáculos que enfrentam para criarem os/as filhos/as, esse menosprezo pode gerar o que Donath (2017) denomina mães arrependidas. As entrevistas que compõem sua pesquisa mostram que a maternidade não está isenta de provocar desgosto ou arrependimento àquelas que a adotam, principalmente porque a pressão para que tenham filhos/as é tão grande que muitas sequer refletem sobre o assunto para efetivamente fazerem uma escolha. Boa parte de suas entrevistadas, mulheres israelenses, confessa não entender por que desejaram ser mães, e que essa decisão faz cada vez menos sentido conforme percebem as consequências da maternidade em suas vidas. Ser mãe, conforme averigua Brown (2010), implica o sentimento de ambivalência e seus derivados: cobrança social, ansiedade e culpa. É viver socialmente vigiada dentro e fora de casa (ou das mídias sociais). A maternidade revela-se distante da representação estática e idealizada que parte significativa da cultura midiática e do imaginário popular the imprimem.

Ao contrário das mães que discorrem sobre a ambivalência materna, as mães arrependidas admitem que a maternidade foi um erro. Mesmo amando os/as filhos/as, reconhecem que seriam mais felizes sem eles/elas. Por sua vez, o senso comum concebe a ideia de que não mães podem se arrepender de não terem tido filhos/as, mas não a de que uma mãe possa se ver arrependida por tê-los/las. Para além de "uma violação flagrante das normas afetivas maternais" (Donath, 2017: 128), o arrependimento "marca o 'caminho não tomado', arrepender-se de ser mãe indica que há na verdade caminhos que a sociedade proíbe às mulheres de tomarem, eliminando a priori vias alternativas como a não maternidade" (ibidem: 13). 
Apesar disso, a existência de estruturas socioeconômicas que dificultam o cotidiano de quem tem filhos/as é uma constante no Sul global. Falta de creches, precariedade de serviços públicos, alta mensalidade das escolas, rigoroso ideal materno e dificuldade para mães manterem ou conseguirem emprego são alguns dos problemas no cenário brasileiro. Uma pesquisa da Escola de Economia e Finanças da Fundação Getúlio Vargas realizada entre 2009 e 2012 mostrou que $48 \%$ das mães brasileiras perdem o emprego após a licença-maternidade ${ }^{14}$ e parte considerável das mulheres vê as oportunidades de trabalho reduzidas após se tornarem mães. ${ }^{15}$

Tal conjuntura - aliada à ausência de políticas dirigidas aos pais, como, por exemplo, licença-paternidade não transferível, obrigatória e igualitária, junto à carência de ativa participação paterna no cotidiano de seus/suas filhos/as - ajuda a entender a crescente recusa e/ou adiamento da maternidade a nível mundial, sendo as taxas de natalidade de países classificados como subdesenvolvidos cada vez mais próximas às de nações tomadas por desenvolvidas (United Nations, 2017). No Brasil, o índice de mulheres sem filhos/as em 2014 era de $38,4 \%$, o maior da última década. ${ }^{16}$ O percentual de casais sem filhos/as também aumentou, passando de $15,2 \%$ em 2005 para $20 \%$ em 2015. ${ }^{17}$ Apesar disso, as não mães ainda são minoria no país, e é comum reportarem, especialmente nas mídias sociais, casos de preconceito diante de sua opção por não ter filhos/as ou da impossibilidade de gerá-los/las ou adotá-los/las (Souza, 2017).

Considerando-se que o estímulo seja o mecanismo do funcionamento social dominante na contemporaneidade, o de não ser mãe seria eficaz. Afinal, o número de mulheres sem filhos/as está subindo, o que indicaria maior estímulo à não maternidade. No entanto, é preciso atentar para alguns aspectos: as não mães permanecem como minoria em todos os países do mundo; essa quantidade tende a diminuir, pois muitas das mulheres contabilizadas enquanto sem filhos/as, com o decorrer dos anos, acabam tendo (por violência, acidente ou escolha) ou adotando crianças; e, mais importante, a maioria da população feminina ainda se torna mãe. O estímulo

\footnotetext{
${ }^{14}$ Cf. Alves, Isabela (2017), " $48 \%$ das mães brasileiras perdem o emprego após licença-maternidade", Observatório do Terceiro Setor, 28 de novembro. Consultado a 12.07.2019, em https://bit.ly/2Paz9Ak.

15 Cf. Martins, Thays (2018), "Mercado de trabalho fecha portas para grávidas e mães com filhos pequenos", Correio Braziliense, 4 de março. Consultado a 12.07.2019, em https://bit.ly/ 3lYltYp.

${ }^{16}$ CBN - Globo (2016), "Número de mulheres que decidem não ter filhos atinge o maior índice dos últimos dez anos”, 16 de julho. Consultado a 12.07.2019, em https://glo.bo/2UEoyUz.

17 UOL Notícias (2016), "Em dez anos, residências de casais com filhos diminuem no país, aponta IBGE”, 2 de dezembro. Consultado a 19.10.2020, em https://bit.ly/2HdOyQO.
} 
pró-maternidade continua muito mais eficaz, mesmo diante do aumento de mulheres sem filhos/as.

A idealização da maternidade é apontada por Ramírez-Ramírez (2013) enquanto uma das razões para que as jovens mexicanas escolham não ser mães. Outro motivo para a sobrecarga materna e a recusa/adiamento da maternidade é a visão cultural da imagem da mãe que, em países como Itália e Alemanha, encarnam a abnegação da qual várias mulheres procuram se afastar (Badinter, 2011). A relevância atribuída à maternidade pelos brasileiros é indicada por Scavone (2004), para quem a questão da escolha ou recusa da maternidade - e, podemos acrescentar, de determinados modelos maternos e de maternagem - continua crucial para a emancipação feminina no Brasil. Interesses governamentais, como o controle demográfico, muitas vezes tornam o acesso a meios contraceptivos quase uma imposição estatal, sobretudo à população mais pobre..$^{18}$ Já a legislação prevê que as gestações brasileiras só podem ser interrompidas em três casos - risco de vida à mãe, estupro e anencefalia do feto -, sendo que $57 \%$ dos hospitais indicados pelo governo para aborto legal se negam a realizar o procedimento. ${ }^{19}$

No Brasil, a importância concedida à maternidade, sobretudo biológica, também se percebe no aumento da demanda por reprodução assistida desde 2014 (Queiroz, 2018). Os maiores solicitantes do procedimento são casais heterossexuais e lésbicos, estes últimos respondendo pelo maior percentual de crescimento, $279 \%$ (entre 2015 e 2016). Neste mesmo período, o segundo maior percentual é de mulheres solteiras, com aumento de $114 \%$ nos pedidos. Além de revelar que a família brasileira passa a abranger configurações diferentes do núcleo familiar heteronormativo historicamente construído, estes dados indicam que, entre as mulheres com condições financeiras para realizá-lo, trata-se de um investimento que estão dispostas a empreender, mesmo que se encontrem fora de alguns modelos femininos normativos (serem lésbicas e/ou escolherem a maternidade solo). Por outro lado, ainda entre as mulheres favorecidas, o desamparo às mães evidencia-se em iniciativas como as do grupo Parent in Science, ${ }^{20}$ que atenta para as dificuldades que várias cientistas enfrentam para conduzirem suas pesquisas em universidades brasileiras depois de terem filhos/as.

\footnotetext{
${ }^{18}$ Casos de laqueadura forçada são registrados desde a década de 1990, como se vê em Cruz, Eliana Alves (2018), "O caso Janaína me lembrou que o Brasil já fez esterilização em massa - com apoio dos EUA", The Intercept Brasil, 18 de julho. Consultado a 22.07.2019, em https://bit.ly/2McRwoO.

${ }^{19}$ Conforme visto em Marie Claire (2019), " $57 \%$ dos hospitais indicados pelo governo para aborto legal se negam a realizar o procedimento”, Globo, 20 de junho. Consultado a 22.07.2019, em https://glo.bo/2Rrw5kN.

${ }^{20}$ Disponível em https://bit.ly/2UhtU2I. Consultado a 12.07.2019.
} 
O ideal feminino contemporâneo não abrange o exigente modelo materno que se popularizou nas últimas décadas, constituindo um conjunto de expectativas incompatível com a maternagem em tempo integral. A criança, concebida como fonte de realização, pode revelar-se um obstáculo à mulher com ambições. A superestima dos deveres maternos agrava esse quadro (Badinter, 2011). Permeados de responsabilização pelo bem-estar dos/das filhos/as e pela necessidade de oferecer uma maternagem o mais eficiente possível, os estilos de vida configuram categorias pertinentes para pensar a maternidade de forma ampla: a segurança de seguir o roteiro social da mulher (constituir família, se tornar uma mãe dedicada) versus o discurso de liberdade (fazer o que deseja, quando e como deseja).

O "poder" de escolha do qual as mulheres do Ocidente capitalista se beneficiam causa dilemas, embates e crises. Toda escolha implica perdas, embora ninguém deseje perder nada. Queremos - e somos constantemente estimulados/as a - exercer vontades, inclusive contraditórias. Como a de ser, ao mesmo tempo, mãe e não mãe. Todavia, o fato de alguém contemporâneo cultivar desejos não significa que serão contemplados. É o caso das mães e não mães involuntárias. Mulheres que, por algum (ou mais de um) motivo, não conseguiram realizar sua vontade de não ter filhos/as ou seu almejo de tê-los/las.

Embora mães e não mães brasileiras denunciem a pouca atenção social que recebem, estas últimas costumam ser menos discutidas. Apesar de ao longo de diferentes momentos históricos terem sempre existido mulheres não mães, estas costumavam ser omitidas tanto dos registros oficiais quanto dos artísticos, sendo geralmente representadas mais como exemplo a não ser seguido. As narrativas hoje produzidas por não mães em diferentes mídias, sobretudo nas digitais, rebatem essa invisibilidade histórica, apontando para as consequências negativas que a não maternidade, mesmo voluntária, tem na vida das mulheres (Souza, 2019):

a) Perda de amizades - mães também relatam que as perdem, mas o número de mulheres que têm filhos/as é muito superior às sem-filhos/as, pelo que se torna mais provável construir redes de contato entre mães, inclusive em substituição às que foram perdidas. Boa parte das vezes, não mães não conseguem formar núcleos exclusivos, adequando-se às agendas e necessidades das amigas com filhos/as para preservar o convívio com elas.

b) Estigma social - a maternidade está entre as premissas mais esperadas e previsíveis da vivência feminina. Apesar de alguns modelos maternos e de maternagem terem sido historicamente alvos de estigmatização (e alguns ainda o serem), o fato de não ser mãe 
impede que uma mulher se adeque às normas hegemônicas tanto maternas quanto femininas.

c) Rejeição enquanto parceiras - já que a maioria das pessoas deseja filhos/as, não enxergam como um par adequado alguém que não os almeje. Mães solo relatam a dificuldade e o preconceito enfrentados ao se relacionarem com quem não quer lidar com os/as filhos/as que já possuem. Todavia, boa parte desses/as parceiros/as espera que a companheira tenha filhos/as com eles/as em algum momento - o que exclui as que pretendem permanecer não mães (ibidem). Mesmo em casais que não planejam filhos/as, a cobrança externa para que se tornem pais/mães é muito presente.

d) Possível falta de amparo na velhice - apesar de as discussões sobre a maternidade constantemente demandarem colaboração de toda a sociedade (incluindo as não mães) para criar e educar as crianças, jovens e/ou dependentes que a compõem, pouco se debate acerca dos cuidados que pessoas sem filhos/as precisarão em idade avançada, e como a sociedade (junto ao Estado) poderia melhor ampará-las. Problema que já se manifesta, por exemplo, no Japão: cresce o número de idosos/as nipônicos/as que cometem pequenos crimes para se abrigarem em cadeias, por não terem quem se responsabilize diretamente por seu bem-estar ou lhes dê apoio financeiro. ${ }^{21}$

Nota-se que, mais uma vez, mães e não mães compartilham aspectos da normatividade materna, expressos de formas distintas. Entre elas, porém, a sensação de desamparo representa uma constante. Para além do que foi apresentado neste artigo, pode-se apontar mais um fator para tal conjuntura: a misoginia que ainda permeia as dinâmicas das instituições públicas, do mercado capitalista e do cotidiano social, condenando aquelas que se reconhecem e se apresentam como mulheres a situações de precariedade e exclusão. Ainda assim, iniciativas femininas (e/ou feministas) buscam amenizar injustiças históricas, especialmente visíveis no Sul global. As discussões acerca da maternidade se alinham a tais empreendimentos e, no Brasil, têm se mostrado importantes meios de debater demais aspectos da vivência feminina.

\section{Considerações finais}

As manifestações acerca da maternidade aqui apresentadas a retratam enquanto campo de tensões, valores e disputas simbólicas acionado por

${ }^{21}$ Cf. BBC News Brasil (2019), "Aposentados na cadeia: os idosos japoneses que se esforçam para serem presos”, 1 de fevereiro. Consultado a 12.07.2019, em https://bbc.in/2tE6U31. 
manifestações culturais populares e midiáticas transnacionais. Indicam, ainda, que a maternidade não diz respeito apenas às mães, mas a todas as mulheres, uma vez que desempenha relevante papel na construção de seus projetos de vida. Por fim, relacionam-se a reflexões sobre parentalidade corresponsável, paternidade cuidadora e funções masculinas, enquanto movimento e teoria dialogantes com demandas sobre maternidade/ /maternagem tanto no campo personalista quanto nos campos simbólico e político.

Refletir sobre as implicâncias de ser ou não ser mãe é um movimento empreendido por um número crescente de brasileiras que, em diálogo com práticas de países do Norte e do Sul global, partilham essas reflexões em postagens, artigos (jornalísticos, científicos ou livres), entrevistas, lives (vídeos feitos ao vivo postados em mídias sociais) e documentários.

Maternidade e não maternidade configuram, portanto, partes do mesmo todo, relacionado a conjunturas socioculturais, demográficas, econômicas, políticas e mercadológicas, para além de influências regionais, familiares, religiosas, afetivas, midiáticas e do cotidiano social. Em última instância, relacionam-se a toda a sociedade. Por um lado, tanto as futuras gerações (os/as filhos/as) quanto as não mães em idade avançada ou com necessidades especiais precisarão ocupar pautas, serviços e espaços públicos. Por outro, também será necessário (re)pensar as imagens, demandas e atribuições associadas às que tiveram filhos/as, bem como às que não o fizeram. Reflexões que se mostram cada vez mais manifestas no Brasil contemporâneo.

Revisto por Alina Timóteo

\section{Referências bibliográficas}

Badinter, Elisabeth (2011), O conflito: a mulher e a mãe. Rio de Janeiro: Record. Tradução de Véra Lúcia dos Reis.

Brown, Ivana (2010), “Ambivalence of the Motherhood Experience”, in Andrea O'Reilly (org.), Twenty First Century Motherhood: Experience, Identity, Policy, Agency. New York: Columbia, 121-139.

Butler, Judith (1990), Gender Trouble: Feminism and the Subversion of Identity. London: Routledge.

Carneiro, Rosamaria (2011), "Feminismos e maternidades: (des)encontros e (re)significados; subjetividades maternas e feministas em questão", Anais eletrônicos do XXVI Simpósio Nacional de História. São Paulo: ANPUH. Consultado a 12.07.2019, em http://www.snh2011.anpuh.org/resources/anais/14/1300805202_ARQUIVO_ CARNEIRO,Rosamaria.ANPUH2011.pdf. 
Donath, Orna (2017), Mães arrependidas: uma outra visão da maternidade. Rio de Janeiro: Civilização Brasileira. Tradução de Marina Vargas.

Douglas, Susan; Michaels, Meredith (2004), The Idealization of Motherbood and How It Has Undermined All Women: The Mommy Myth. New York: Free Press.

Dramali, Bianca Leite (2018), "Gestação (d)e excessos: notas iniciais sobre a relação com a materialidade e consumo na gravidez”. Trabalho apresentado no 41 . $^{\circ}$ Congresso Brasileiro de Ciências da Comunicação, 2 a 8 de setembro, Joinville, Brasil. Consultado a 12.07.2019, em https://bit.ly/2Gfa3gB.

Giddens, Anthony (1991), Modernity and Self-Identity. Cambridge: Polity.

Leal, Tatiane (2015), "A mulher poderosa: construções da vida bem-sucedida feminina no jornalismo brasileiro”. Dissertação de Mestrado em Comunicação e Cultura, Programa de Pós-graduação em Comunicação e Cultura, Escola de Comunicação, Universidade Federal do Rio de Janeiro, Rio de Janeiro, Brasil.

Lemos, André (2002), Cibercultura, tecnologia e vida social na sociedade contemporânea. Porto Alegre: Sulina.

Macedo, Ana Gabriela; Amaral, Ana Luísa (orgs.) (2005), Dicionário da crítica feminista. Porto: Edições Afrontamento.

Mendonça, Maria Collier de (2014), "A maternidade na publicidade: uma análise quantitativa e semiótica em São Paulo e Toronto”. Tese de Doutorado em Comunicação, Programa de Pós-graduação em Comunicação e Semiótica, Pontifícia Universidade Católica de São Paulo, São Paulo, Brasil.

Meruane, Lina (2018), Contra os filhos: uma diatribe. São Paulo: Todavia.

O'Reilly, Andrea (2013), “It Saved My Life': The National Association of Mothers' Centres, Matricentric Pedagogy and Maternal Empowerment", Journal of the Motherhood Initiative for Research and Community Involvement, 4(1), 185-209.

Queiroz, Christina (2018), "Gestações transnacionais - Demanda por reprodução assistida amplia entrada de material genético estrangeiro no Brasil”, Pesquisa FAPESP, 19(269), 70-75.

Rago, Margareth (1998), "Epistemologia feminista, gênero e história”, in Miriam Pillar Grossi; Joana Maria Pedro (orgs.), Masculino, feminino, plural: gênero na interdisciplinaridade. Florianópolis: Ed. Mulheres, 21-41.

Rago, Margareth (2004), "Feminismo e subjetividade em tempos pós-modernos", in Cláudia de Lima Costa; Simone Pereira Schmidt (orgs.), Poéticas e políticas feministas. Florianópolis: Ed. Mulheres, 31-41.

Ramírez-Ramírez, Valentina (2013), "Una aproximación sociocultural a la no-maternidad voluntaria”. Dissertação de Mestrado em Comunicación de la Ciencia y la Cultura, Departamento de Estudios Socioculturales, Instituto Tecnológico y de Estudios Superiores de Occidente, Tlaquepaque, Jalisco, México.

Scavone, Lucila (2001), "A maternidade e o feminismo: diálogo com as ciências sociais”, Cadernos Pagu, 16, 137-150. 
Scavone, Lucila (2004), "Dar a vida e cuidar da vida: sobre maternidade e saúde”, in Dar a vida e cuidar da vida: feminismo e ciências sociais. São Paulo: Editora UNESP, 127-140. Sibilia, Paula (2010), "Em busca da felicidade lipoaspirada: agruras da imperfeição carnal sob a moral da boa forma”, in João Freire Filho (org.), Ser feliz hoje: reflexões sobre o imperativo da felicidade. Rio de Janeiro: Editora FGV, 195-212.

Souza, Ana Luiza de Figueiredo (2016), "Mas, afinal, o que é o Tinder? - Um estudo sobre a percepção que os usuários têm do aplicativo”, Verso e Reverso, 30(75), 186-195.

Souza, Ana Luiza de Figueiredo (2017), "Afinidades e divergências ao debater a maternidade no Facebook: um estudo de caso nas páginas 'Desintoxicação do romantismo' e 'Já falou para seu menino hoje?’”, Anais eletrônicos do X Simpósio Nacional da ABCiber. São Paulo: ECA/USP, 479-505. Consultado a 19.10.2020, em http://www. abciber.org.br/anais-abciber-2017.pdf.

Souza, Ana Luiza de Figueiredo (2018), "Maternidade, culpa e ruminação em tempos digitais”, Revista Ártemis, XXV(1), 89-112.

Souza, Ana Luiza de Figueiredo (2019), “'Me deixem decidir se quero ou não ser mãe!’: narrativas pessoais de mulheres sobre a maternidade nas mídias sociais”. Dissertação de Mestrado em Comunicação, Programa de Pós-graduação em Comunicação, Instituto de Arte e Comunicação Social, Universidade Federal Fluminense, Niterói, Brasil.

Tomaz, Renata Oliveira (2016), "Vendem-se conselhos: poder pastoral, mídia e maternidade”, Rizoma, 4(1), 196-207.

United Nations (2017), “United Nations World Fertility Data 2017”. S.1.: Department of Economic and Social Affairs, Population Division.

van Zoonen, Liesbet (2012), "I-Pistemology: Changing Truth Claims in Popular and Political Culture”, European Journal of Communication, 27(1), 56-65.

Artigo recebido a 23.07.2019

Aprovado para publicação a 30.06 .2020

\section{Ana Luiza de Figueiredo Souza}

Doutoranda no Programa de Pós-graduação em Comunicação, Universidade Federal Fluminense Rua Professor Marcos Waldemar de Freitas Reis, s/n. Bloco A, 4. ${ }^{\circ}$ andar, CEP: 24210-201,

São Domingos, Niterói/RJ, Brasil

Contacto: analuizafigueiredosouza@id.uff.br

ORCID: https://orcid.org/0000-0002-1368-3184 


\section{Maternal Tensionings in Contemporaneity: Articulations with the Brazilian Scenario}

From the global North to the global South, there is increasing debate on motherhood, with Brazil emerging as a fruitful field of research in this context. As a country that preserves conservative ideologies and also absorbs new technological and cultural manifestations, it displays particular phenomena that establish dialogue with foreign practices. This article explores the sociocultural conjunctures around the wealth of discussions about motherhood, aiming to find similarities and divergences between dynamics of Brazil and other countries. To do so, the paper contextualizes historical movements that have led to the current situation of women and motherhood in the capitalist West; examines the tensions in the coexistence between contemporary and historically constructed practices; and discusses to what extent the processes of continuity or rupture between them occur.

Keywords: Brazil; female identity; feminism; motherhood; womanhood; women's health.

\section{Tensions maternelles à la contemporanéité : articulations avec le scénario brésilien}

Du Nord au Sud global, le débat sur la maternité augmente. Dans ce contexte, le Brésil est un exemple utile en tant que domaine de recherche. Comme pays qui préserve aussi bien des idéologies conservatrices qu'il absorbe les nouvelles manifestations technologiques et culturelles, il présente des phénomènes particuliers qui dialoguent avec des pratiques étrangères. Cet article explore les conjonctures socioculturelles autour de l'augmentation des discussions à propos de la maternité, visant à trouver des similitudes et des divergences entre les dynamiques brésiliennes et celles d'autres pays. Pour cela, il contextualise les mouvements historiques qui ont conduit à la situation actuelle des femmes et de la maternité dans l'Occident capitaliste ; examine les tensions de la coexistence entre les pratiques contemporaines et historiquement construites ; et discute dans quelle mesure les processus de continuité ou de rupture se produisent entre elles. Mots-clés: Brésil; condition féminine; féminisme; identité féminine; maternité; santé de la femme. 